\title{
Investimentos em pesquisa, inovação em saúde e tecnologia: revisão da literatura
}

\author{
Itamires Benício dos SANTOS ${ }^{(1)}$ \\ Brunna Verna Castro GONDINHO ${ }^{(1)}$
}

${ }^{(1)}$ Faculdade de Saúde Pública, Universidade de São Paulo - USP, São Paulo, SP, Brasil.

Recebido: 28 jan 2019 Aceito: 10 fev 2019

Autor de correspondência: itamiresbenicio@gmail.com

Conflito de interesses: Os autores declaram não haver nenhum interesse profissional ou pessoal que possa gerar conflito de interesses em relação a este manuscrito.

\section{Resumo}

O aumento progressivo do investimento em saúde, visa a melhoria na qualidade de vida da população e possui uma dinâmica que envolve grande valor socioeconômico. O número de novas tecnologias lançadas no mercado é crescente, porém, tem seu ciclo de vida curto. A elevação dos custos em saúde representa, portanto, um desafio para as fontes pagadoras governamentais e privadas. Objetivo: este trabalho teve por objetivo investigar se é possível avaliar o retorno nos investimentos em pesquisa, inovação em saúde e tecnologia. Método: diante deste contexto, por meio de estudos científicos indexados em bases de dados, foi realizada uma revisão sistemática da literatura a partir da busca por periódicos nacionais e internacionais considerados referência até o momento atual. Os critérios utilizados para a seleção da amostra foram: artigos no período de 1980 a 2018. Nos idiomas português, inglês ou espanhol. Que abordassem a temática Investimentos de Pesquisa, Inovação em Saúde e Tecnologia. A estratégia de busca foi norteada pela pergunta de pesquisa inicial "Quais os investimentos de Pesquisa e Inovação com Tecnologia de Alto Custo no Sistema Único de Saúde (SUS)?". A primeira etapa da estratégia de busca caracterizou a definição dos descritores e os classificou em: População, Fenômeno e Contexto. A segunda fase foi realizar uma procura individualizada de cada descritor, em seguida uma nova procura com a combinação de todos os descritores. Totalizando apenas 3 artigos, mediante a escassez de materiais, foi elaborada uma nova seleção de documentos o que resultou numa mudança da pergunta de pesquisa inicial. A terceira fase foi uma nova busca, planejada com base nos termos da pergunta de pesquisa inicial. Foram selecionados os seguintes termos: Investimentos, Inovação em Saúde, Tecnologia, Alto Custo e SUS. A quarta fase da estratégia de busca, foi o rastreio de periódicos nas bases de dados com cada termo de pesquisa (investimento, inovação em saúde, tecnologia, alto custo e SUS) de modo individualizado em seguida foram combinados os termos entre si. A permuta de todos os termos simultaneamente resultou em 0 artigos, após retirar o termo (SUS) encontraram-se um artigo, em seguida foi removido o termo (Alto Custo). Resultando na sintaxe ((tw:(investimento\$)) $A N D$ (tw:(tecnologia)) $A N D$ (tw:(inovacao em saude)). Totalizaram 112 periódicos potenciais, e estes não contemplavam os termos da pergunta inicial, por esse motivo a pergunta de pesquisa foi modificada para: "Como se avaliam os investimentos em pesquisa, inovação em saúde e 
tecnologia, relatados pela literatura?". E deu-se início a análise de qualidade e extração de dados. Total da amostra inicial 112 artigos, desses 25 periódicos foram excluídos em razão do título e quatro por duplicidade. Resultando em 82 artigos para avaliação dos resumos, dos quais foram excluídos 25. Restando 57 artigos elegíveis para análise profunda, após a análise, foram excluídas 33 publicações que não preenchiam os critérios de inclusão. Considerações finais: o que resultou em 24 artigos que foram adquiridos na integra para análise de qualidade e extração de dados. Cujos conteúdos variaram, desde os motivadores extrínsecos e intrínsecos envolvidos na inovação, como o ganho de reputação dos investidores ou incentivos monetários, das empresas nacionais que estão ampliando sua participação no mercado de saúde e intensificando seus investimentos em pesquisa e desenvolvimento, apoiados por políticas públicas de inovação que é um elemento decisivo para a redução da vulnerabilidade e da dependência estrutural em saúde de países em desenvolvimento como é o caso do Brasil diante do cenário internacional. Outro tema levantado na análise dos artigos fala sobre a introdução de novas tecnologias oferecerem a promessa de avançar a medicina. Diante disso inovações nem sempre são adequadamente avaliadas quanto a sua eficácia, efetividade e custos, antes da sua incorporação pelos serviços e a implementação inadequada poderia retardar o progresso da medicina e o acesso dos pacientes aos cuidados necessários. Os gestores utilizam algumas ferramentas de avaliação como a análise de custo-efetividade (CE), como guia para alocação de recursos gastos, as atividades inovadoras muitas vezes ocorrem em hospitais e, portanto, são incorporados ao hospital cenário organizacional. $O$ investimento estratégico em atividades inovadoras pode ser rentável a longo prazo se as inovações fornecerem pioneirismo e vantagens competitivas mediante a dificuldade em obter lucros a curto prazo de inovações geradas internamente, justificando que ás vezes os hospitais hesitam em investir em novas pesquisas devido o CE. Outro ponto levantado, foi a dificuldade das empresas com novos dispositivos médicos, para vendê-los a custo acessível aos hospitais e sistemas de saúde ou para encontrar o reembolso de operadoras e seguradoras privadas. Concluindo, os principais achados da presente revisão, o setor de tecnologia médica é um campo enorme e diversificado, A demanda por pesquisa e desenvolvimento de novas tecnologias é crescente, em razão dos benefícios proporcionados pelo avanço científico. Há necessidade de um forte engajamento das partes interessadas, pois, a saúde é vista simultaneamente como um bem social, econômico e espaço de acumulação de capital. O financiamento é custeado pelos setores públicos e privado, e a má gestão do sistema pode resultar em malefícios para o bem estar da população e ineficiência no uso de recursos financeiros. A escassez de artigos como foi demonstrada na metodologia é outro fator que gera impacto direto no conhecimento difundido sobre o tema.

Descritores: Investimentos em Saúde; Inovações; Tecnologia. 